\title{
Rational size and stability analysis of horizontal isolated pillars in deep mining from caving to filling method
}

\author{
Fan Feng ${ }^{1,2,3}$, Xibing $\mathrm{Li}^{3}$, Shaojie Chen ${ }^{1}$, Dingxiao Peng ${ }^{3}$, and Zhuang Bian ${ }^{1 *}$ \\ ${ }^{1}$ College of Energy and Mining Engineering, Shandong University of Science and \\ Technology, Qingdao, Shandong, 266590, China \\ ${ }^{2}$ School of Resources and Civil Engineering, Northeastern University, Shenyang, Liaoning, \\ 110819, China \\ ${ }^{3}$ School of Resources and Safety Engineering, Central South University, Changsha, Hunan \\ 410083, China
}

\begin{abstract}
For mining using the caving and filling methods in metal mines, determining a suitable size for the isolated pillars - the connecting part of the extension from shallow to deep-is crucial for ensuring safety and efficiency. Considering actual cases involving deep caving and cut-and-fill mining in the Chifeng Hongling lead-zinc mine in Inner Mongolia, China, the reserved thickness range of the horizontal isolation layer is obtained via theoretical analysis. On this basis, the pre-processing software HyperMesh is used to build a high-precision hexahedral grid model of the mining area, and the three-dimensional geological model of the mining area is imported into the finite-difference software FLAC3D. The stress field, displacement field, and plastic area evolution law of pillars (horizontally isolated pillars and adjacent rib pillars) in the stope of the ninth middle section after excavation are analyzed via numerical simulation inversion of the selected scheme of horizontal isolated pillars. The numerical simulation results show that the scheme employed to retain the upper horizontal isolated pillars in the ninth middle section involves reserving thicknesses of $8 \mathrm{~m}$ and $32 \mathrm{~m}$ at average ore body thicknesses of $15 \mathrm{~m}$ and $35 \mathrm{~m}$, respectively. These results can provide theoretical guidance and a basis for safe and efficient mining of deep metal mines.
\end{abstract}

\section{Introduction}

The caving method has the advantages of a relatively simple production process, low production cost, and safe production, and it is used worldwide. However, with the increase in mining depth, the surface subsidence area is expanding, and the geological conditions

${ }^{*}$ Corresponding author: $\underline{s k d r c b @, s d u s t . e d u . c n ~}$ 
have been deteriorating [15]. At the same time, the deep ground pressure is obviously increased, which results in the serious destruction of roadways, the occasional occurrence of rocks bursting, serious collapses of the roof of the stope and hanging wall rock mass, resulting in an increase in mineral loss and dilution, in some cases permanently preventing minerals from being mined [14]. In order to ensure the safety of personnel, increase environmental protection, and reduce the cost of land acquisition and relocation, an increasing number of caving method mines will be converted to cut-and-fill stoping after entering the deep $[7,8]$.

In order to achieve the continuous and stable production and construction safety of mines, and to realize a smooth transition from the caving method to cut-and-fill stoping, horizontal isolation pillars with a specific thickness should be reserved at the joint. When determining the size of the isolated pillars, the greater the thickness of the isolated pillars, the safer will be the mining process. However, overly thick isolated pillars will inevitably cause wastage of mineral resources, the need for extensive excavation and investment in the isolated pillars, a large loss and dilution rate, and a low recovery rate of about $40 \%$. If the thickness of the isolated pillars is too small, it may be damaged, resulting in the following: (1) the sudden failure of the isolated pillars, which will impact and destroy the lower filling body, making the lower ore body complex and difficult to mine; (2) the sudden instability of the isolated pillars, which will produce compressed air, directly threatening the safety of workers and equipment; (3) for large water mines, it will cause the water in the shallow mining stage to recharge to the deep; (4) As a result, the acceleration of stress transfer from the upper part to the deep part, and the ground pressure during deep mining is intensified [4, $6,11,12,16]$.

To determine the safe thickness of the horizontal isolated pillars, many scholars have established mechanical models based on mathematical and physical methods [5], thus providing a theoretical basis for scientifically determining the thickness of a roof in the goaf and for evaluating the roof stability in the goaf. Representative methods include the load transfer line intersection method, thickness span ratio method, fracture arch theory method, rubber theory estimation method, calculation method of Bogoliubov theory, and the analysis method of elasticity. However, the thickness of the isolated pillars calculated using the above theoretical analysis method is quite different and has high discreteness. Therefore, it needs to be verified and analyzed through numerical simulations and other methods. It should be noted that most of the existing numerical simulation analyses often simplify the ore body model, that is, they do not consider the surface relief, ore body thickness, dip angle changes, and other factors, resulting in a decreased authenticity and reliability of the numerical simulation results. Therefore, it is important to adopt advanced numerical modeling technology to accurately build a three-dimensional (3D) geological model of the mining area as well as to lay a solid foundation for the subsequent numerical simulation analysis $[13,17]$.

In the early stage of the Chifeng Hongling lead-zinc mine in Inner Mongolia, the combined caving method was used to excavate the ore body, and a enormous subsidence pit was produced on the surface, as shown in Figure 1 [13]. At present, the mine has gradually entered the deep mining stage; if no protective measures are adopted, the main buildings on the surface will enter the moving band. In order to prevent further expansion of the moving band, and considering potential disasters resulting from the disturbance of three high and one deep, subsequent cut-and-fill stoping was adopted to excavate the deep ore body. In order to achieve a safe and stable transition, horizontal isolation pillars with a specific thickness should be reserved to isolate the waste rocks in the upper goaf. In this study, based on several classical mechanical models that are widely used domestically and overseas, a preliminary selection of the retention scheme is made for the size of the isolated pillars $[1,2,3]$. Then, numerical simulation technology is used to make a comprehensive comparison of the scheme of retaining the isolated pillars, and the stability of the pillars in the deep stope is analyzed. The results of this study can provide some theoretical guidance for the safe and efficient mining of similar mines. 

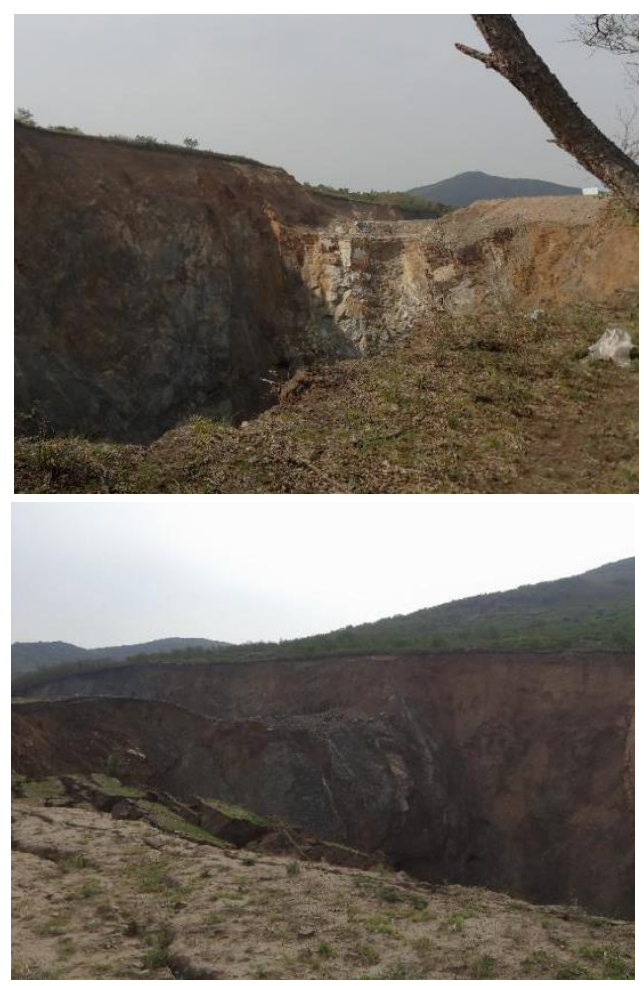

Fig. 1. Surface subsidence pit formed using the Caving Method.

\section{Project overview}

The lead-zinc mine in Inner Mongolia is a skarn-type polymetallic mine. The overall strike of the ore body is $59^{\circ}$ to the northeast, inclines to the northwest with a dip angle of $60^{\circ}-80^{\circ}$, an average dip angle of $75^{\circ}$, and a strike length of $1350 \mathrm{~m}$. The ore body is composed of 1 \# ore vein and 2 \# ore vein, and the mineral is hard and stable. Among them, the average thickness of the 1 \# ore vein is $24.6 \mathrm{~m}$, and the average thickness of the 2 \# ore vein is 18.8 $\mathrm{m}$. The marble is located in the hanging wall of the 1 \# ore vein and the footwall of the 2 \# ore vein, and the rock is hard and stable with an average thickness of $74.4 \mathrm{~m}$. the sandy slate is located in the footwall of the 1 \# ore vein and the hanging wall of the 2 \# ore vein, the rock is hard and stable between the exploration lines 13 to 15 , and there is also a long rock porphyry ore vein ore-free area with an average thickness of $14.4 \mathrm{~m}$. The stability of the ore rock is generally good, which is characteristic of ore rock with simple geological conditions, and except for some geological structural areas, no support is required.

At present, the development of the mine extends to the middle section of 555, and the ore body of the middle section of 705 is being stoped. The current mining method employed in the mine is a stage open stoping combined caving mining method, as shown in Figure 2. The ore body below the middle section of 705 is distributed to the east of feldspar porphyry dyke rock. As the roof and bottom pillars were stoped using the stage open stoping combined caving mining method, the goafs are connected with each other to form a large-scale goaf. The covering rock mass and surrounding rock continue to subsidence, which further leads to a large-scale subsidence area on the surface. According to statistics, the area of the surface subsidence area has reached $52416 \mathrm{~m}^{2}$, which seriously endangers the surface personnel and jeopardizes the safety of the buildings. Therefore, in order to control the surface subsidence area and the moving area, a cut-and-fill stope was adopted to 
stope the deep ore body, and a certain thickness of horizontal isolation pillars below the middle section of 705 was reserved.

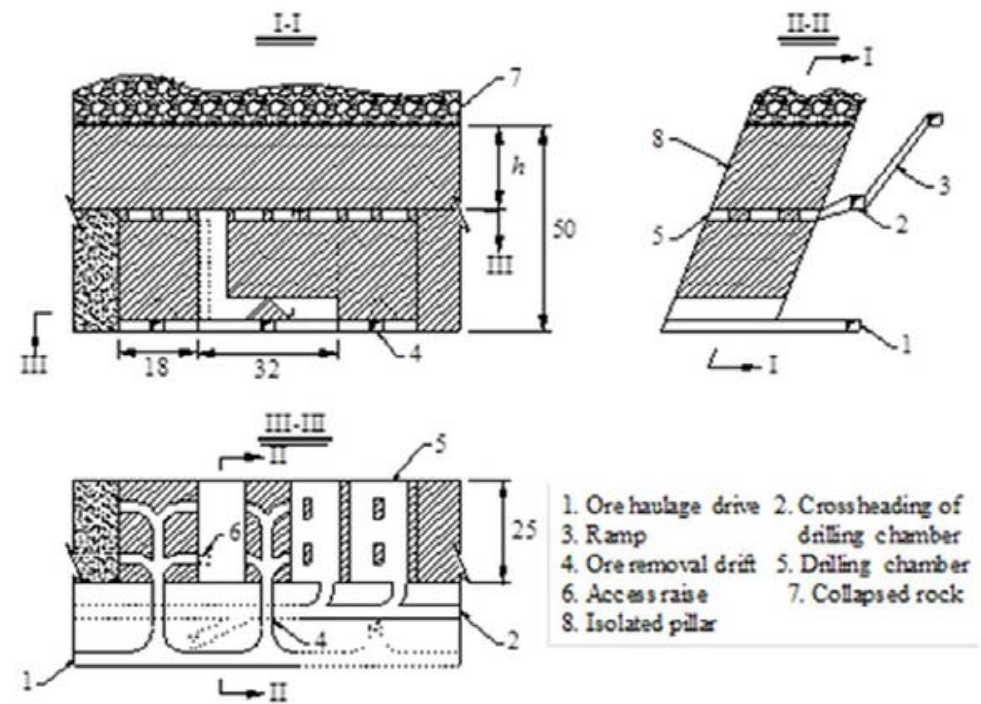

Fig. 2. Schematic diagram of stage open stoping combined caving mining method.

Upon analyzing the deep middle section map of the mining area and the mineral exploration development profile map, it was found that the ore body distribution below the middle of section 8 is relatively complex. The thickness of the ore body close to the $+705 \mathrm{~m}$ level is mainly between 8 and $50 \mathrm{~m}$ and varies considerably along the strike direction. Considering that $50 \%$ of the ore body below $+705 \mathrm{~m}$ adopts the method of sublevel drilling stage stoping and subsequent cut-and-fill stoping (the average thickness of the ore body is $15 \mathrm{~m}), 20 \%$ of the ore body adopts the methods of shrinkage stoping and subsequent cut-and-fill stoping, and $30 \%$ of the ore body adopts the method of stage stoping and subsequent cut-and-fill stoping (the average thickness of the ore body is $35 \mathrm{~m}$ ). Further, the proposed length of the stope room is $32 \mathrm{~m}$, and the pillars are $18 \mathrm{~m}$ without considering the rib pillars.

Because the ore body above $+705 \mathrm{~m}$ is excavated using the caving mining method, without supporting measures, the surrounding rock in the upper goaf will be damaged and will collapse owing to the combined effects of mining stress and excavation unloading. In addition, a certain weight of waste rock will be formed at the bottom[9]. Therefore, in the next stage of mining, the overlying uniform load on the horizontal isolated pillars (for the convenience of calculation, it is considered that the pillars bear a uniform load) is mainly applied by the waste rock from the surrounding rock of the goaf. From calculations, the value of the uniform load on the overlying horizontal isolated pillars is approximately 6.6 $\mathrm{MPa}$.

\section{Development of a reasonable scheme for retaining horizontally isolated pillars based on theoretical analysis}

In this section, the limit span method, K. B. Rubenet method, B. H. Bogoliubov method, length width ratio plate beam method, loose coefficient theory, plate beam theory, load intersection line method, Proctor arch method, and thickness span ratio method are used to 
calculate and analyze the thickness of horizontally isolated pillars [10]. Table 1 shows the calculation formula and a brief overview of principles behind each theory. Based on comprehensive laboratory test results of rock mechanics parameters and analysis results of rock mass quality classification, the rock mass engineering mechanical parameters are determined, and the mechanical parameters of the rock mass are shown in Table 2.

Table 1. Theoretical calculation methods and results

\begin{tabular}{|c|c|c|c|}
\hline $\begin{array}{l}\text { Theoretic } \\
\text { al method }\end{array}$ & Calculation formula & Parameter interpretation & $\begin{array}{c}\text { Thickness } \\
\text { of } \\
\text { isolated } \\
\text { pillars } \\
\text { (m) }\end{array}$ \\
\hline $\begin{array}{l}\text { Limit } \\
\text { span } \\
\text { method }\end{array}$ & $h_{p}=W\left(\frac{\gamma_{s} W n}{2 \sigma_{t}}+3.3 \sqrt{\frac{\gamma_{s} h_{s} n}{\sigma_{c}}}\right)$ & $\begin{array}{l}h_{p} \text { - thickness of isolated } \\
\text { pillars; } W \text {-stope room } \\
\text { width; } \sigma_{\mathrm{t}} \text {-tensile strength } \\
\text { of isolated pillar mineral, } \\
\mathrm{MPa} ; \sigma_{\mathrm{c}} \text {-compression } \\
\text { strength of isolated pillar } \\
\text { mineral, MPa; } \gamma_{s} \text { - bulk } \\
\text { density of waste rock, } \\
\mathrm{kN} / \mathrm{m}^{3} ; h_{\mathrm{s}} \text { - height of the } \\
\text { collapsed rock or packed } \\
\text { pile, m; } n \text {-safety } \\
\text { coefficient, the open stope } \\
\text { is adopted, taking } 3 \text {. }\end{array}$ & $\begin{array}{r}\text { Thick ore } \\
\text { bo } \\
\text { dy: } \\
25 \\
\text { Thin ore } \\
\text { body: } 10\end{array}$ \\
\hline $\begin{array}{l}\text { K.B. } \\
\text { Rubenet } \\
\text { method }\end{array}$ & $H=K \frac{0.25 \gamma_{2} B^{2}+\left(\gamma_{2}^{2} B^{2}+800 \sigma_{n 5} g\right)^{0.5}}{98 \sigma_{n 5}}$ & $\begin{array}{l}H \text {-required thickness of } \\
\text { isolated pillars, m; } \\
K \text {-safety coefficient, } \\
\text { taking } 3 ; \gamma_{2}-\text { bulk density } \\
\text { of roof rock, t/m } \mathrm{m}^{3} ; \mathrm{B} \text {-goaf } \\
\text { span, m; } \sigma_{\mathrm{n} 5}=\sigma_{\mathrm{c}} / K_{0} K_{3} \text { block } \\
\text { is rock strength limit under } \\
\text { bending condition, } K_{0}=2-3 \text {, } \\
K_{3}=7-10, \sigma_{\mathrm{c}}-\text { uniaxial } \\
\text { compressive strength of } \\
\text { rock, MPa; g-pressure of } \\
\text { the filling body above the } \\
\text { isolated pillars on the } \\
\text { isolated pillars, MPa. }\end{array}$ & $\begin{array}{r}\text { Thick ore } \\
\text { bo } \\
\text { dy: } \\
29.6 \\
\text { Thin ore } \\
\text { body: } 9.8\end{array}$ \\
\hline $\begin{array}{c}\text { B.H. } \\
\text { Bogoliub } \\
\text { ov } \\
\text { method }\end{array}$ & $H=K \frac{\gamma_{p} W_{0}^{2}+\left(\gamma_{p} W_{0}^{2}+16 \sigma_{n 5} P\right)^{\frac{1}{2}}}{q \sigma_{n 5}}$ & $\begin{array}{c}H-\text { thickness of horizontal } \\
\text { isolated pillars, m; } \\
P \text {-dynamic load caused by } \\
\text { blasting rock mass, } \\
P=r H_{\mathrm{Y}} K_{\mathrm{n}}\left(K_{\mathrm{c}}+K_{\mathrm{nep}}\right) / K_{\mathrm{p}} ; \\
H_{\mathrm{Y}}-\text { gradient height, taking } \\
12 \mathrm{~m} ; r \text { - blasting index, } \\
\text { taking } 1.5 ; K_{\mathrm{c}}, K_{\mathrm{nep}}, K_{\mathrm{n}} \text { and } \\
K_{\mathrm{p}} \text {-reduction coefficient of } \\
\text { bench height, over drilling } \\
\text { coefficient, dynamic load } \\
\text { coefficient and ore rock } \\
\text { loose coefficient during } \\
\text { blasting, combined with } \\
\text { previous research, } K_{\mathrm{c}} \text { is } 0.1, \\
K_{\text {nep }} \text { is } 1.2, K_{\mathrm{n}} \text { is } 2, K_{\mathrm{p}} \text { is } 1.3 .\end{array}$ & $\begin{array}{r}\text { Thick ore } \\
\text { bo } \\
\text { dy: } \\
76.4 \\
\text { Thin ore } \\
\text { body: } 12.3\end{array}$ \\
\hline
\end{tabular}




\begin{tabular}{|c|c|c|c|}
\hline $\begin{array}{l}\text { Length } \\
\text { width } \\
\text { ratio } \\
\text { plate } \\
\text { beam } \\
\text { method }\end{array}$ & $\begin{array}{l}\text { 1. } H_{n}=\frac{L_{n}}{8} \times \frac{\gamma L_{n}+\sqrt{\gamma^{2} L_{n}^{2}+16 \sigma\left(P+P_{1}\right)}}{\sigma} \\
\text { (The ratio of the open stope length to } \\
\text { width is greater than 2) } \\
\qquad 2 . \quad \sigma=\frac{6 M_{\max }}{b h^{2}} \\
\text { (The ratio of the open stope length to } \\
\text { width is equal to or less than 2) }\end{array}$ & 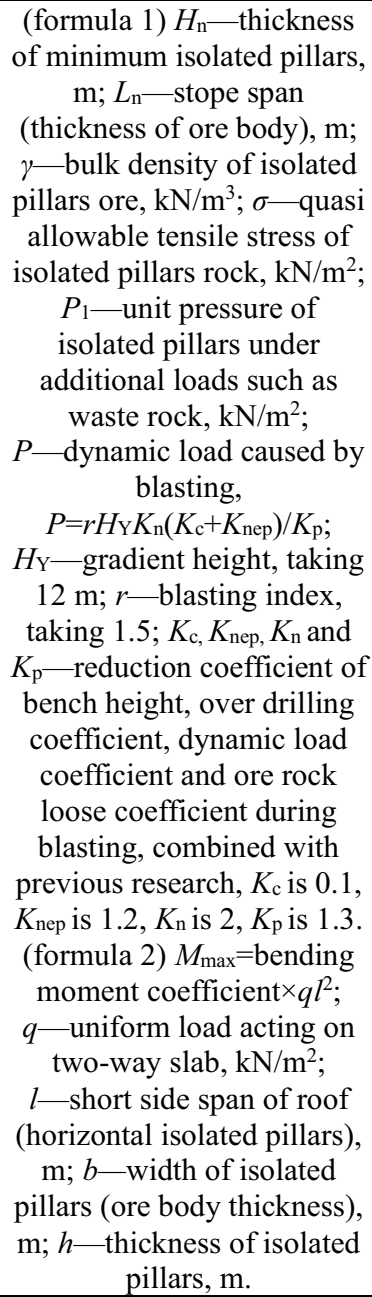 & $\begin{array}{r}\text { Thick ore } \\
\text { bo } \\
\text { dy: } \\
25 \\
\text { (Accordin } \\
\mathrm{g} \text { to } \\
\text { formula 2) } \\
\\
\text { Thin ore } \\
\text { body: } 7.5 \\
\text { (Accordin } \\
\mathrm{g} \text { to } \\
\text { formula 1) }\end{array}$ \\
\hline $\begin{array}{c}\text { Loose } \\
\text { coefficien } \\
\text { t theory }\end{array}$ & $H_{p}=\frac{H_{k}}{1-K_{p}}$ & $\begin{array}{l}H_{\mathrm{k}}-\text { void height, m; } \\
K_{\mathrm{p}} \text {-loose coefficient, } \\
\text { taking } 0.2 \text {. Assuming that } \\
\text { the thickness of horizontal } \\
\text { isolated pillars } H_{\mathrm{p}} \text { is } \mathrm{x} \mathrm{m} \\
\text { the goaf height is }(50-\mathrm{x}) \\
\mathrm{m}, \text { there is }(50-\mathrm{x})=0.8 \mathrm{x} \text {. }\end{array}$ & 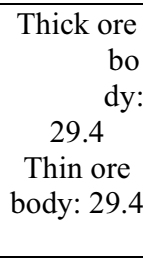 \\
\hline $\begin{array}{l}\text { Plate } \\
\text { beam } \\
\text { theory }\end{array}$ & $H_{p}=\frac{K \gamma_{p} W_{0}}{20 \sigma_{t}}$ & $\begin{array}{l}H_{\mathrm{p}} \text { - thickness of isolated } \\
\text { pillars, m; } \sigma \text { - uniaxial } \\
\text { tensile strength of isolated } \\
\text { pillars mineral, } \mathrm{MPa} ; \\
K \text {-safety coefficient, } \\
\text { taking } 2.5 ; W_{0}-\text { goaf span, } \\
\text { i.e., thickness of ore body, } \\
\mathrm{m} ; \gamma_{\mathrm{p}} \text { - bulk density of } \\
\text { isolated pillars rock, } \mathrm{kN} / \mathrm{m}^{3} \text {. }\end{array}$ & 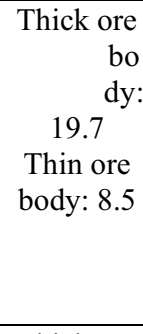 \\
\hline $\begin{array}{l}\text { Load } \\
\text { intersecti } \\
\text { on line } \\
\text { method }\end{array}$ & $h=\frac{K L}{2 \tan \beta}$ & $\begin{array}{l}h \text { - thickness of minimum } \\
\text { isolated pillars, m; } L \text {-goaf } \\
\text { span, i.e., thickness of ore } \\
\text { body, } \mathrm{m} ; \beta \text {-angle between } \\
\text { load transfer line and }\end{array}$ & $\begin{array}{r}\text { Thick ore } \\
\text { bo } \\
\text { dy: } \\
27.5-32 \\
\text { Thin ore }\end{array}$ \\
\hline
\end{tabular}




\begin{tabular}{|c|c|c|c|}
\hline & & $\begin{array}{c}\text { vertical center line of roof, } \\
\text { taking } 30^{\circ}, 32^{\circ}, \text { and } 35^{\circ} ; \\
K \text { - safety coefficient, } \\
\text { taking } 2.5 .\end{array}$ & $\begin{array}{c}\text { body: } \\
11.8-15.5\end{array}$ \\
\hline $\begin{array}{l}\text { Proctor } \\
\text { arch } \\
\text { method }\end{array}$ & $H_{y}=\frac{b+h \cdot \tan (45-\varphi / 2)}{f}$ & $\begin{array}{l}H_{\mathrm{y}} \text { - thickness of minimum } \\
\text { isolated pillars, m; } b \text {-half } \\
\text { of stope width (thickness of } \\
\text { ore body), m; } h \text {-maximum } \\
\text { height of stope, m; } \\
\varphi \text {-internal friction angle of } \\
\text { rock, }{ }^{\circ} \text {; } \\
f \text { - Protodyakonov coefficie } \\
\text { nt of rock. }\end{array}$ & $\begin{array}{r}\text { Thick ore } \\
\text { bo } \\
\text { dy: } \\
28 \\
\text { Thin ore } \\
\text { body: } 12\end{array}$ \\
\hline $\begin{array}{c}\text { Thickness } \\
\text { span ratio } \\
\text { method }\end{array}$ & $\frac{h}{K L} \geq 0.5$ & $\begin{array}{c}h-\text { safe thickness of } \\
\text { horizontal isolated pillars, } \\
\text { m; } L \text {-stope span (thickness } \\
\text { of ore body), m; } K \text {-safety } \\
\text { coefficient, taking } 2.5,1.5, \\
1.7 .\end{array}$ & $\begin{array}{r}\text { Thick ore } \\
\text { bo } \\
\text { dy: } \\
21-35 \\
\text { Thin ore } \\
\text { body: } \\
9-15\end{array}$ \\
\hline
\end{tabular}

Table 2. Physical and mechanical parameters of numerical simulation (after reduction)

\begin{tabular}{|c|c|c|c|c|c|c|c|c|}
\hline Lithology & $\begin{array}{c}\text { Modulu } \\
\text { s of } \\
\text { elasticit }\end{array}$ & $\begin{array}{c}\text { Bulk } \\
\text { modu } \\
\text { lus }\end{array}$ & $\begin{array}{c}\text { Poiss } \\
\text { on } \\
\text { ratio }\end{array}$ & $\begin{array}{c}\text { Inter } \\
\text { nal } \\
\text { frictio }\end{array}$ & $\begin{array}{c}\text { Densi } \\
\text { ty } \\
\text { (g/cm }\end{array}$ & $\begin{array}{c}\text { Compress } \\
\text { ion } \\
\text { strength }\end{array}$ & $\begin{array}{c}\text { Tensil } \\
\text { e } \\
\text { streng }\end{array}$ & $\begin{array}{c}\text { Cohesi } \\
\text { on } \\
\text { (MPa) }\end{array}$ \\
\hline Marble & 11.64 & 8.43 & 0.27 & 47 & 2.663 & 7.86 & 0.7 & 1.2 \\
\hline Hanging wall & 18.83 & 11.62 & 0.23 & 36 & 2.665 & 15.44 & 0.9 & 1.3 \\
\hline Football rock & 11.22 & 7.19 & 0.24 & 34 & 2.701 & 10.21 & 0.802 & 1.1 \\
\hline Slate & 18.81 & 10.81 & 0.21 & 49 & 2.77 & 17.02 & 0.9 & 1.5 \\
\hline Ore body & 21.26 & 11.43 & 0.19 & 50 & 3.565 & 25.33 & 2 & 1.8 \\
\hline Feldspar & 21.26 & 11.43 & 0.19 & 50 & 3.565 & 25.33 & 2 & 1.8 \\
\hline
\end{tabular}

At the same time, the required parameters are substituted into the above nine theoretical formulas to calculate the corresponding thicknesses of horizontally isolated pillars for a thick ore body $(35 \mathrm{~m})$ and a thin ore body $(15 \mathrm{~m})$, as shown in Table 1 . It can be seen from Table 1 that for thin ore bodies, the thickness of horizontal isolated pillars obtained by each theoretical solution is ranges mainly between 7.5-15.5 m (except for the value of $29.8 \mathrm{~m}$, which was calculated using the loose coefficient theory). For the thick ore body, the thickness of the horizontal isolated pillars obtained by each theoretical solution ranges mainly between 19.7-35 $\mathrm{m}$ (except for the value of $76.4 \mathrm{~m}$, which was calculated using the B.H. Bogoliubov method). It can be seen that the thickness of the horizontal pillars obtained via theoretical calculation is highly discrete; therefore, it is impossible to obtain a more accurate thickness value for the isolated pillars. Therefore, the scope of application of the theoretical method is limited; its single result can only be used as a reference, but it needs to be analyzed and verified through subsequent numerical simulations. In summary, the above results are compared and classified, and considering the grid size, it is proposed to set up two retention schemes for a thin ore body and three retention schemes for a thick 
ore body (see Table 3 for details), and these schemes are substituted into subsequent numerical simulations.

Table 3. Thickness of selected horizontal isolated pillars

\begin{tabular}{cc}
\hline $\begin{array}{c}\text { Thickness of isolated pillars } \\
\text { of thin ore body / } \mathbf{m}\end{array}$ & $\begin{array}{r}\text { Thickness of isolated pillars } \\
\text { of thick ore body / } \mathbf{~}\end{array}$ \\
\hline 8 & 20 \\
12 & 25 \\
& 32 \\
\hline
\end{tabular}

\section{Numerical simulation inversion of the retaining scheme of deep horizontal isolated pillars}

\subsection{Three-dimensional geological model of mine and establishment of numerical model}

The finite-difference method software FLAC3D was used to perform the numerical simulation of mining. According to the plan map of each middle section, surface topographic map, and section map of each exploration line of the lead-zinc mine, a high-precision simulation model of the mine was built using the pre-processing software HyperMesh, and the grid was divided. Because HyperMesh is not directly imported into the interface of FLAC3D, in this simulation, the grid file is converted to the FLAC3D grid file using MATLAB.

The model coordinate axis $\mathrm{X}$ is perpendicular to each exploration line, the coordinate axis $\mathrm{Y}$ is parallel to each exploration line, and the vertical direction is the $\mathrm{Z}$ direction. For convenience of modeling, a point on exploration line 6 is taken as the coordinate origin, and the elevation $+455 \mathrm{~m}$ in the $\mathrm{Z}$ direction is taken as the bottom of the model. The overall length and width of the model are $900 \mathrm{~m}$ and $600 \mathrm{~m}$, respectively. According to the material characteristics, the model is divided into an ore body, marble, feldspar porphyry, and slate. HyperMesh is used to divide the high-quality hexahedral grid, and all grid nodes are coupled with each other. The model grid is shown in Figure 3. The numerical simulation adopted the Mohr Coulomb yield criterion. In the early stage of the mine, an indoor rock mechanics experiment as well as structural plane investigation and analyses were carried out, and the quality of the rock mass was graded. Table 2 shows the physical and mechanical parameters of the rock mass. The boundary condition of the static displacement is set, and the $\mathrm{X}$-axis displacement is fixed on the plane of both ends of the model in the $\mathrm{X}$-axis direction, the Y-axis displacement is fixed on the plane of both ends of the model in the $\mathrm{Y}$-axis direction, and the $\mathrm{X}, \mathrm{Y}$, and $\mathrm{Z}$ displacements are fixed on the bottom boundary of the model. Core obtained by drilling, the Kaiser effect method is used to obtain the distribution of crustal stress in the mining area, and the azimuth consistency of the maximum horizontal principal stress at different buried depths is satisfactory. Table 4 shows the crustal stress data measured on site; the relationship between the $3 \mathrm{D}$ crustal stress and buried depth can be obtained as follows: 


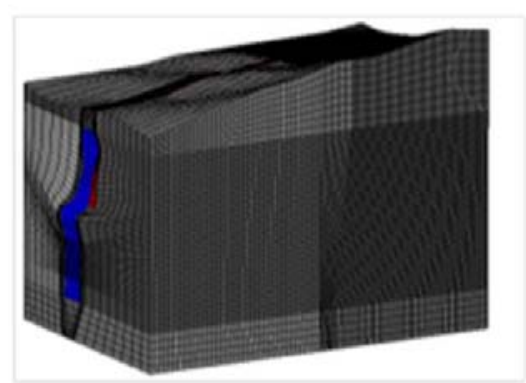

(a)

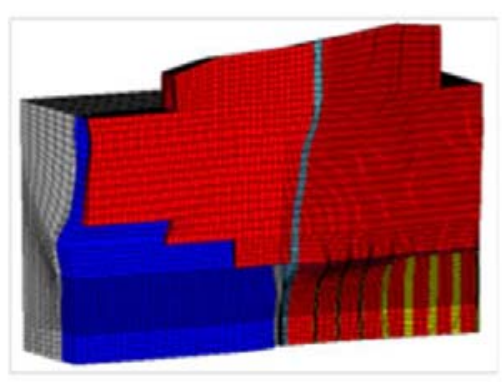

(b)

Fig. 3. Numerical simulation calculation model grid. (a) Model external grid (b) Model internal grid

$$
\left.\begin{array}{l}
\sigma_{z}=0.0279 h, \\
\sigma_{1}=0.0256 h+10.202, \\
\sigma_{3}=0.0233 h+1.4743 。
\end{array}\right\}
$$

where: $\sigma_{\mathrm{z}}$-vertical principal stress, $\mathrm{MPa} ; \sigma_{1}-$ maximum horizontal principal stress, MPa; $\sigma_{3}$ - minimum horizontal principal stress, $\mathrm{MPa}$; and $\mathrm{h}$ - buried depth, $\mathrm{m}$.

The core drilling elevation is $+1068 \mathrm{~m}$, and in this model, the zero plane of the Z-axis coordinate is set to $+455 \mathrm{~m}$. If the above formula is converted into the stress input mode in FLAC3D, and if the specified pressure stress is negative and the average direction angle $\theta=$ $8.7^{\circ}$ is selected as the calculation basis, then the stress in the $\mathrm{X}$ and $\mathrm{Y}$ directions can be calculated as follows:

$$
\left.\begin{array}{l}
\sigma_{x}=-16.619+0.0243 z, \\
\sigma_{y}=-17.486+0.0246 z, \\
\sigma_{x y}=4.7656-0.00149 z \circ
\end{array}\right\}
$$

\subsection{Calculation scheme and steps of numerical simulation}

The mining method of the deep middle section is that the block section with the thickness of 5-15 $\mathrm{m}$ adopts sublevel drilling stage stoping and subsequent cut-and-fill stoping, accounting for $30 \%$, the ore block is arranged along the strike, the length of the ore block is $50 \mathrm{~m}$, the width of the ore block is the horizontal thickness of the ore body, the height of the ore block is $50 \mathrm{~m}$, and the width of the rib pillars is $8 \mathrm{~m}$. For the block with ore body thickness $\geq 15 \mathrm{~m}$, stage stoping and subsequent cut-and-fill stoping is adopted, accounting for $50 \%$, layout along the strike, the ore block is $50-\mathrm{m}$ long, the pillars are $18 \mathrm{~m}$, and the stope room is $32 \mathrm{~m}$. The stoping sequence of the stope room is from the center to the two wings. In this numerical simulation, a total of six schemes are selected to set up horizontal isolated pillars: 
(a)

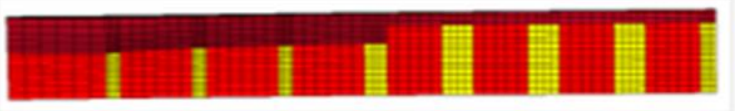

(b)

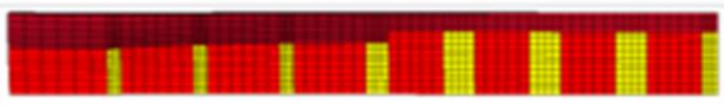

(c)

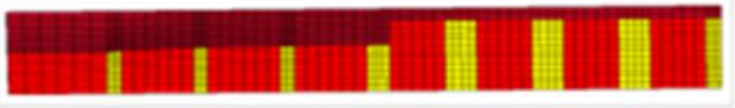

(d)

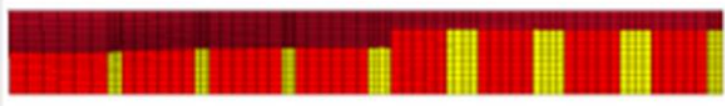

(e)

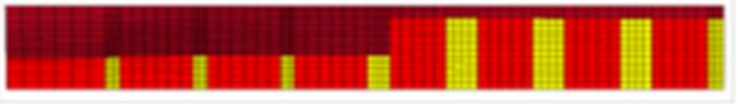

(f)

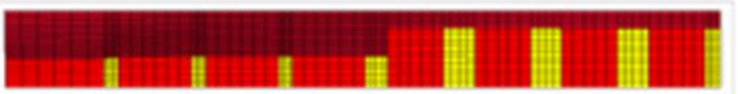

Fig. 4. Scheme for retaining pillars at different levels. Subfigures (a)-(f) correspond to schemes A-F, respectively.

In scheme A, 8-m security pillars are reserved for an ore body with an average thickness of $15 \mathrm{~m}$, and $20-\mathrm{m}$ security pillars are reserved for an ore body with an average thickness of $35 \mathrm{~m}$.

In scheme B, 12-m security pillars are reserved for an ore body with an average thickness of $15 \mathrm{~m}$, and $20-\mathrm{m}$ security pillars are reserved for an ore body with an average thickness of $35 \mathrm{~m}$.

In scheme C, 8-m security pillars are reserved for an ore body with an average thickness of $15 \mathrm{~m}$, and $25-\mathrm{m}$ security pillars are reserved for an ore body with an average thickness of $35 \mathrm{~m}$.

In scheme D, 12-m security pillars are reserved for an ore body with an average thickness of $15 \mathrm{~m}$, and $25-\mathrm{m}$ security pillars are reserved for an ore body with an average thickness of $35 \mathrm{~m}$.

In scheme E, 8-m security pillars are reserved for an ore body with an average thickness of $15 \mathrm{~m}$, and 32-m security pillars are reserved for an ore body with an average thickness of $35 \mathrm{~m}$.

In scheme F, 12-m security pillars are reserved for an ore body with an average thickness of $15 \mathrm{~m}$, and 32-m security pillars are reserved for an ore body with an average thickness of $35 \mathrm{~m}$. The scheme for the retention of pillars is shown in Figure 4.

\subsection{Numerical simulation results of retaining scheme of deep horizontal isolated pillars}

In order to study the stability of deep caving to cut-and-fill horizontal isolated pillars and adjacent rib pillars of a stope room under the most unfavorable conditions, the filling body was not considered in the numerical simulation analysis of different schemes of horizontally isolated pillars. Therefore, this section discusses the use of FLAC3D numerical simulations to obtain the distribution law of the stress field and plastic area of the rib pillars and isolated pillars after the excavation of the ninth middle section stope. 


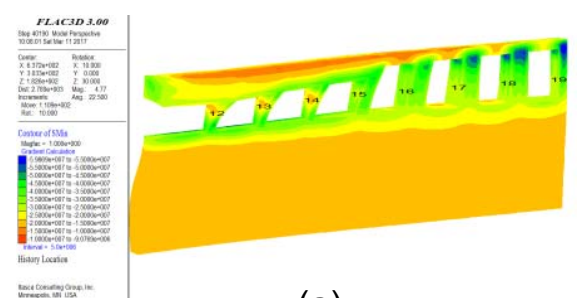

(a)

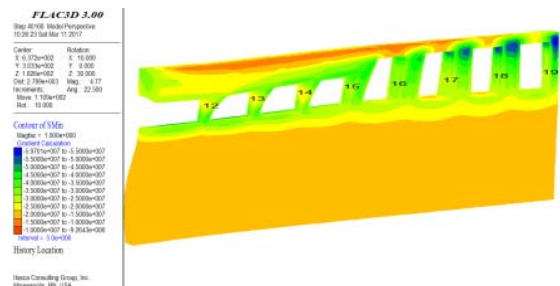

(c)

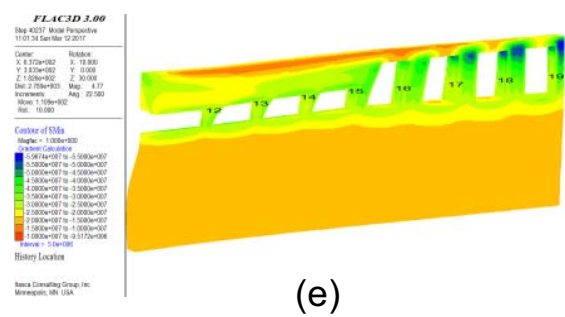

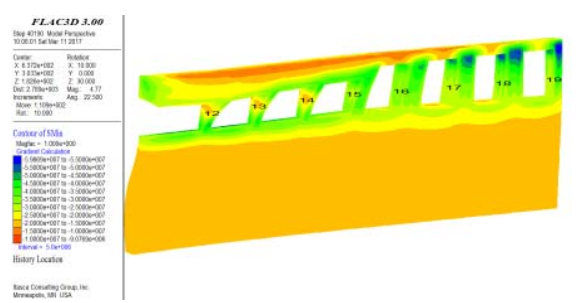

(b)

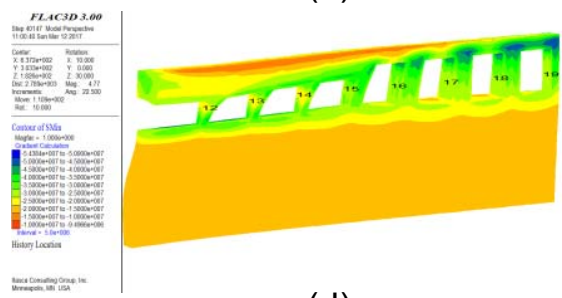

(d)

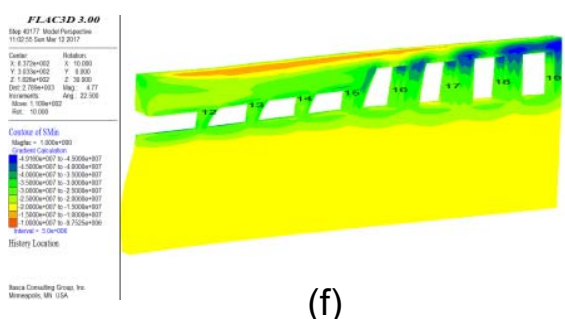

(f)

Fig. 5. Nephogram of maximum principal stress of isolated pillars and rib pillars under different retaining schemes

(1) Stress field analysis

Excavation results in the redistribution of the original rock stress and stress concentration in some areas, especially the rib pillars and the top and bottom plates after the excavation, which can easily lead to the instability and failure of the rock mass structure. Therefore, it is very important to analyze the stress distribution law of the stope in order to evaluate the stability of the excavation structure.

The maximum principal stress diagram shows a prominent stress concentration when the rib pillars are near the roof (horizontal isolated pillars); this stress concentration is particularly evident on the side of the thin ore body, and the maximum principal stress value can reach approximately $50 \mathrm{MPa}$. This means that the connecting top plate of the rib pillars is most likely to be damaged; therefore, necessary measures should be adopted when stoping the ore body in order to reduce the disturbance; otherwise supporting measures should be adopted.

From a comparison of the different schemes, the maximum principal stress value of each rib pillar in scheme $\mathrm{A}$ is the highest. As the thickness of the isolated pillars increases (regardless of whether it is a thick or thin ore body), the degree of stress concentration becoming gradually smaller, indicating that increasing the thickness of the horizontal isolated pillars can effectively inhibit the stress concentration of the rib pillars, and the probability of the rib pillars failure is also reduced.

(2) Displacement field analysis 

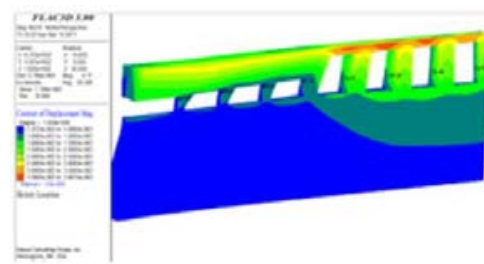

(a)

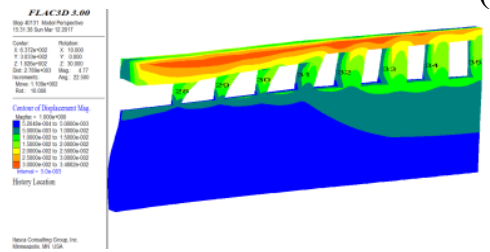

(b)
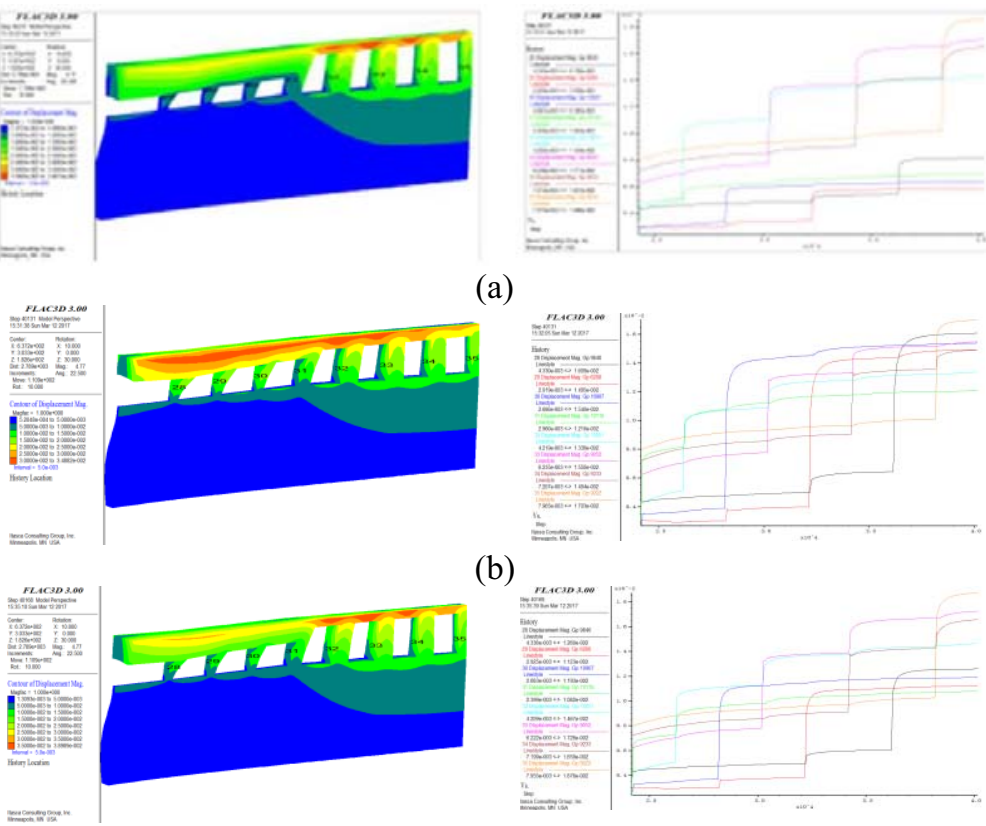

(c)
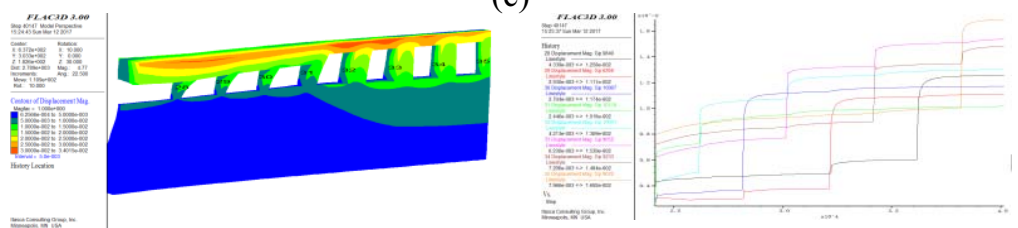

(d)
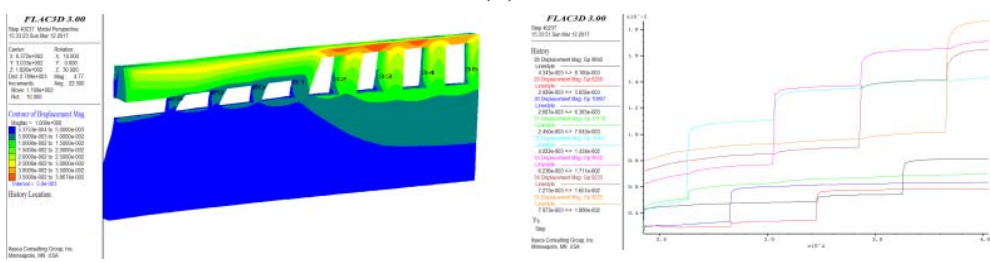

(e)
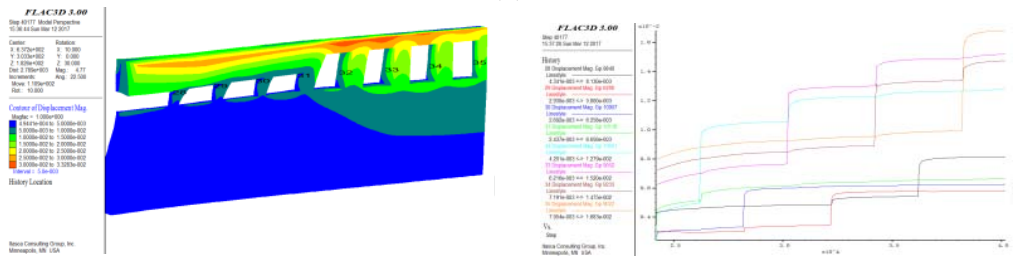

(f)

Fig. 6. Displacement nephogram of isolated pillars and rib pillars under different retention schemes and displacement curves of monitoring points with excavation time. In the figure, (a)-(f) correspond to pillar retention schemes A-F, respectively.

From displacement nephograms of the same scheme, it can be seen that the displacement value at the upper position (close to the roof) of the rib pillars is notably larger than that at other positions of the rib pillars; moreover, the displacement value of the rib pillars between the thick ore body is smaller, while that of the rib pillars in the thin ore body is larger. 
Taking scheme $\mathrm{F}$ as an example, the displacement value of the rib pillars in the thick ore body is between $0.5 \mathrm{~cm}$ and $1 \mathrm{~cm}$, while that in the thin ore body is approximately $2 \mathrm{~cm}$. From the comparison of various schemes, it can be seen that whether it has a thick or thin ore body, when the size of the corresponding isolated pillars is relatively thin, the displacement value of the rib pillars is relatively large. For the rib pillars with the thin ore body, the maximum displacement of the No. 35 monitoring point in scheme A is $2.3 \mathrm{~cm}$, while that of the No. 35 monitoring point in scheme $\mathrm{F}$ is $1.68 \mathrm{~cm}$; for the rib pillars with the thick ore body, the maximum displacement of the No. 28 monitoring point in scheme A is $1.6 \mathrm{~cm}$, while that of the No. 28 monitoring point in scheme $\mathrm{F}$ is $0.8 \mathrm{~cm}$. The numerical simulation results show that with an increased thickness of the horizontal isolated pillars, the lower the displacement value of the pillars in the ninth middle section, the higher the stability.

From the chart showing the variation in the displacement of the monitoring point of each rib pillar with the excavation time step, the displacement value of the rib pillars changes rapidly and then flattens after the stope room excavation. In addition, when the stope room is excavated, the adjacent rib pillars of the stope room will also be affected to a certain extent; thus, the displacement will continue to increase. The displacement value of the rib pillars in the thin ore body increases faster than that in the thick ore body.

Comparing scheme E and scheme F, it can be seen that for the thick ore body, the maximum displacement value of the No. 28 monitoring point in scheme E reaches $0.8 \mathrm{~cm}$, which is the same as that of the No. 28 monitoring point in scheme F; for the thin ore body, the maximum displacement value of the No. 35 monitoring point in scheme $\mathrm{E}$ is $1.86 \mathrm{~cm}$, while that of the No. 35 monitoring point in scheme $F$ is $1.68 \mathrm{~cm}$, the difference between them is only $0.18 \mathrm{~cm}$, which shows that there is little difference in displacement settlement of rib pillars between scheme $\mathrm{E}$ and scheme $\mathrm{F}$.

(3) Plastic area analysis

As mining continues, the stress of the ore body and surrounding rock will be redistributed and will finally reach secondary balance or failure, and the plastic area in the rock body will change accordingly. Table 4 shows the failure of the plastic area of the isolated pillars and the pillars in the ninth middle section of six schemes with the excavation time step.

Table 4 lists the four excavation stages, that is, the Z-direction stress nephogram when the excavation reaches $4000,8000,12000$, and 16000 steps. When the excavation reaches 16000 steps, all the stope rooms in the ninth middle section will have been recovered. An analysis of Table 4 shows the following:

(1) When stoping the first step of the stope room (step 4000), horizontal isolated pillars, rib pillars, and the floor plastic area are not very obvious in each scheme, which shows that the upper isolation pillars of the stope room and the corresponding rib pillars are relatively stable when excavating single- or two-stope rooms. When stoping the second and third steps of the stope room (steps 8000 and 12000), the volume of the plastic area of the isolated pillars and rib pillars began to increase gradually, while the floor of the stope room did not have the appearance of a plastic area. This indicated that the adjacent rib pillars and roof were significantly damaged during the ore body excavation process, while the floor did not have obvious damage. In addition, for the same scheme, the proportion of the roof in the thick ore body and plastic area of adjacent rib pillars is notably smaller than that of the thin ore body. When stoping the fourth step of the stope room (step 16000), the volume of the plastic area will continue to expand, but its degree of expansion and scope will gradually become stable. In view of the plastic area between the horizontal isolated pillars and the adjacent rib pillars after the stope room excavation in the ninth middle section, the volume of the plastic area can be reduced by optimizing the stoping sequence, blasting parameters, and strong mining and filling to prevent further damage to the rock mass.

(2) The plastic area diagram of each scheme shows that the roof damage range is wide, while the rib pillar damage range is relatively narrow. This indicates that necessary support measures should be adopted when stoping the ore body (especially the thin ore body), or the charge quantity should be reduced when stoping the top layer, to ensure the safety of the 
roof.

(3) It can also be seen from the figure that when all of the stope rooms in the middle section are completed, the volume of the plastic area formed by the first two schemes (i.e., scheme A and scheme B) is significantly increased compared with the last four schemes, which indicates that when the thickness of the $20-\mathrm{m}$ security pillars is reserved on the upper part of the thick ore body, its own stability cannot be guaranteed and it is easily damage.

Table 4. Distribution of plastic area in different excavation steps (sequence) for the six schemes

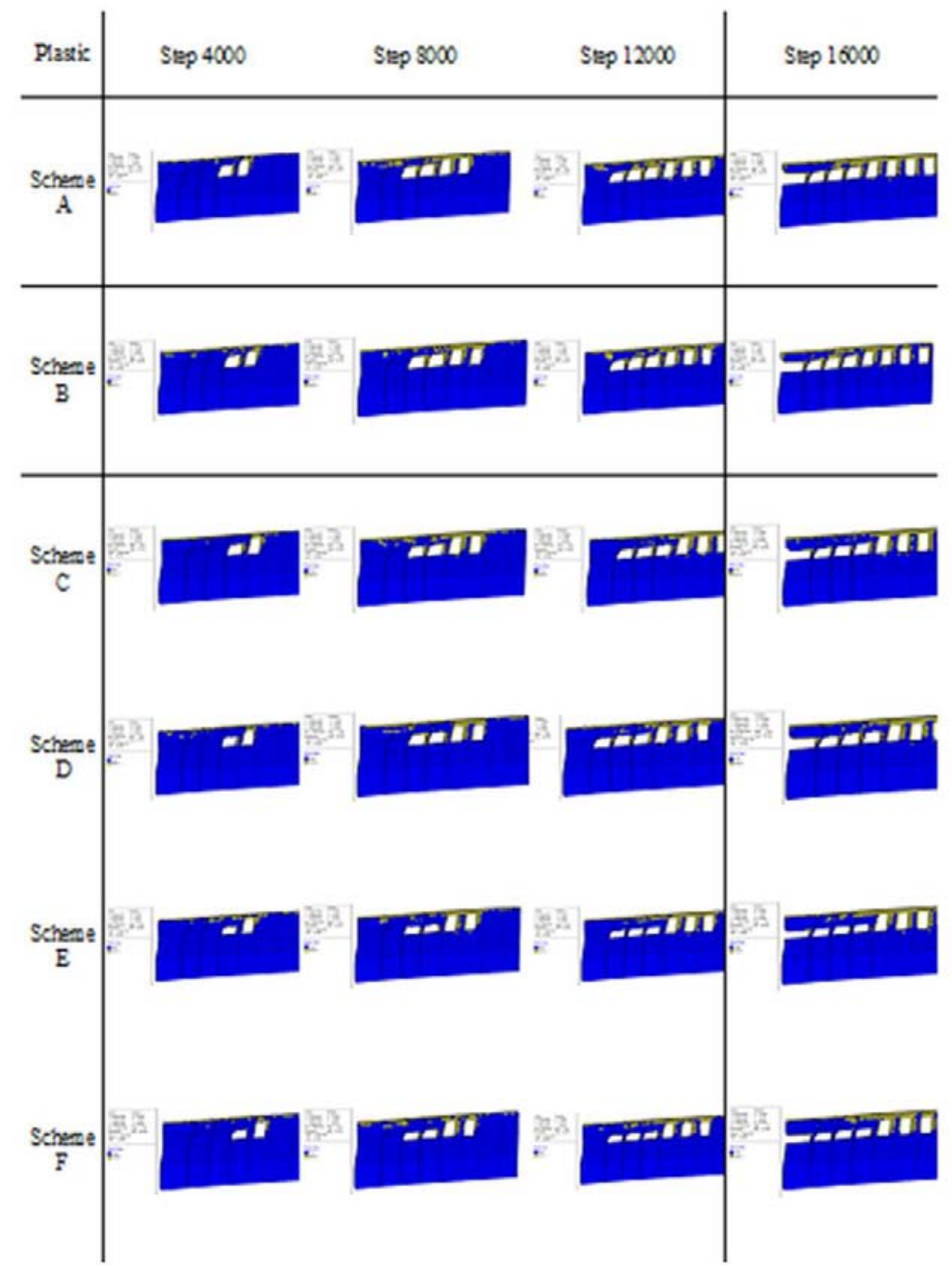


In this section, the fish language in FLAC3D is used to obtain the sum of the total volume of the plastic area of the horizontal isolated pillars and rib pillars, and the sum of the total volume of the horizontal isolated pillars and rib pillars in the ninth middle section of each scheme. The ratio of the volume of the plastic area of the isolated pillars and rib pillars to their total volume (degree of damage) is taken as the consideration factor, as shown in Table 5. It should be noted that the volume of the plastic area in the bottom plate is very small in each scheme; hence, this part is not considered in the total volume of the plastic area. Table 5 shows that as the ore body thickness increases, the overall scope of the plastic area shows a gradually decreasing trend, which indicates that the stability of the horizontal isolated pillars and rib pillars will steadily improve with an increase in the thickness of the isolated pillars. Among them, the total volume of the plastic area in Schemes A and B respectively accounted for $73.3 \%$ and $69.4 \%$ of the total volume of pillars, which indicates that the pillars are damaged over a large range, the bearing capacity of pillars is greatly reduced, the stability is low, and it is not conducive to normal deep stoping. However, schemes $\mathrm{E}$ and $\mathrm{F}$ have the lowest degree of damage, and the difference between them is very small, i.e., $30.8 \%$ and $30.2 \%$, respectively, which shows that there is almost no difference between schemes $\mathrm{E}$ and $\mathrm{F}$ in terms of maintaining the stability of the pillars. Therefore, considering the ore body loss rate, recovery rate, and other factors, it is proposed that the size of pillars be reduced as much as possible. In other words, the final scheme E (8-m security pillars are reserved for an ore body with an average thickness of $15 \mathrm{~m}$, and $32-\mathrm{m}$ security pillars are reserved for an ore body with an average thickness of $35 \mathrm{~m}$ ) is the reasonable size of isolation pillars for deep caving to cut-and-fill.

Table 5. Total volume and degree of damage of pillars and the plastic area of the ninth middle section (schemes A-F)

\section{Scheme A Scheme B Scheme C Scheme D Scheme E Scheme F}

\begin{tabular}{ccccccc}
\hline $\begin{array}{c}\text { Total volume } \\
\text { of plastic }\end{array}$ & 203790 & 200080 & 133610 & 146840 & 102550 & 103620 \\
$\begin{array}{c}\text { Total volume } \\
\text { of pillars }\end{array}$ & 278160 & 288430 & 298890 & 309160 & 332790 & 343070 \\
$\begin{array}{c}\text { Degree of } \\
\text { Degree } \\
\text { damage (\%) }\end{array}$ & 73.3 & 69.4 & 44.7 & 47.5 & 30.8 & 30.2 \\
\hline
\end{tabular}

\section{Conclusion}

The Chifeng Hongling lead-zinc mine, which is located in Inner Mongolia, China, has gradually entered the deep mining stage, and the ground pressure phenomenon is gradually starting to occur; this seriously affects the production and safety of the mine. In this paper, several schemes involving horizontal isolated pillars are first proposed using theoretical analyses, and the reasonable thickness of horizontal isolated pillars is obtained by performing numerical simulation. The main conclusions are as follows:

(1) By using the limit span method, K. B. Rubenet method, B. H. Bogoliubov method, length width ratio plate beam method, loose coefficient theory, plate beam theory, load intersection line method, Proctor arch method, and thickness span ratio calculation method, the reasonable reserved thickness range of the isolation layer is obtained. Among them, for thick ore bodies, the thickness of horizontal isolated pillars obtained by each theoretical solution is varies mainly between 20 and $\sim 35 \mathrm{~m}$, while the reasonable thickness of horizontal isolated pillars corresponding to thin ore bodies varies mainly between 8 and 
$14.2 \mathrm{~m}$. According to the different ore body thickness values and the existing mining technical conditions, the thickness of horizontal isolated pillars can be divided into six schemes, which provide a theoretical basis for the subsequent FLAC3D numerical simulation inversion calculation and scheme optimization.

(2) A large-scale 3D geological model of the goaf and deep ore body is established using HyperMesh modeling software. Then, the high-quality hexahedral grid division of the ore body, marble, feldspar porphyry, and slate was carried out. The ore body model is in agreement with the actual case in the mining area, which is important for the accurate calculation of subsequent numerical simulations.

(3) Several schemes involving the use of horizontal isolated pillars were proposed, and FLAC3D software was used to carry out numerical simulation calculations and inversions for the selected scheme and parameters of isolated pillars, as well as to analyze the stress field, displacement field, and plastic area change rules of the deep ore body (mainly the ninth middle section ore body) and surrounding rock (mainly horizontal isolated pillars and adjacent rib pillars) under each scheme, which provides technical guidance for the reasonable determination of the thickness of horizontal isolated pillars.

(4) It was determined that the scheme for retaining the horizontal isolated pillars in the ninth middle section is 8 -m security pillars are reserved for an ore body with an average thickness of $15 \mathrm{~m}$, and 32-m security pillars are reserved for an ore body with an average thickness of $35 \mathrm{~m}$ (Scheme E). The determination of the scheme aims to reduce the mineral dilution rate and loss rate in the later stages of pillar stoping under the premise of safe operation, which provides a reasonable basis for the safe and efficient stoping of deep caving to cut-and-fill stoping.

\section{Acknowledgments}

The authors would like to acknowledge the financial supports from SDUST Research Fund (2019TDJH101).

\section{References}

1. F. Fan, C. Shaojie, L. Diyuan, H. Songtao, H. Wanpeng, L. Bo, Energy Science and Engineering, 7:6, 2265 (2019)

2. F. Fan, L. Xibing, D. Kun, L. Diyuan, R. Jamal, W. Shaofeng, International Journal of Geomechanics, 20:2, 04019005 (2020)

3. F. Fan, L. Xibing, R. Jamal, P. Dingxiao, L. Diyuan, D. Kun, International Journal of Geomechanics, 19:4, 04019005 (2019)

4. W.P. Huang, C .Li, L.W. Zhang, Q. Yuan, Y.S. Zheng, Y. Liu, Int J Rock Mech Min Sci, 105, 85 (2018)

5. F. Deyuan, L. Xuesheng, T. Yunliang, S.Shilin, G.Qingheng, Y.Lei, X. Qiang, Energies, 12, 2032 (2019)

6. Z. Jinhai, L. Bo, C. Juntao, J. Ning, Arabian Journal of Geoscience., 13:11, 404 (2020)

7. S. Mohamed Amine, L. Li, Journal of Rock Mechanics and Geotechnical Engineering.; 9:3, 490 (2017)

8. W. Jiachen, Z .Jinwang, L. Zhaolong, International Journal of Rock Mechanics and Mining Sciences, 88, 273 (2016)

9. A. A. Neverov, S.A. Neverov, A.M. Nikolsky, M. V. Tishkov, S.A. Shchukin, Challenges for Development in Mining Science and Mining Industry, 262, UNSP 012051 (2019) 
10. F. Fan, L. Diyuan, L. Xibing, G. Zhongping, W. Shaofeng, C. Ying, International Journal of Geomechanics, 17:7, 04017004 (2017)

11. W. Bonan, D. Faning, G. Shuancheng, H. Rongbin, M. Yanping, C. Wei, International Journal of Rock Mechanics and Mining Sciences, 130, 104340 (2020)

12. Y. Shengli, L. Lianghui, D. Xujie, Natural Hazards, 100:2, 757 (2020)

13. L. Xibing, W. Dongyi, L. Chongjin, L. Zhixiang, Advances in Civil Engineering, 2019, 2724370 (2019)

14. T. Ganqiang, L. Mingxing, Z. Xiufeng, Z. Rui, Z. Zhonghua, International Journal of Rock Mechanics and Mining Sciences, 113, 163 (2019)

15. D. Yangyang, C. Congxin, X. Kaizong, Y. Kuoyu, S. Chaoyi, Z. Xianwei, China, 77:10, $362(2018)$

16. Y. Yongkang, M. Yanrong, J. Chunxu, K. Tianhe, G. Xingyun, Advances in Civil Engineering, 2018, 6871820 (2018)

17. Y. Changping, S. Jonny, J. Daniel, Tunnelling and Underground Space Technology, 68, 167 (2017) 